\title{
Análise do balanço hídrico superficial e avaliação da disponibilidade potencial da água para o rodeio do gado no Uruguai entre 1980 e 2006
}

\author{
Analysis of the surface water balance and evaluation of the potential \\ availability of water for livestock rodeo in Uruguay between 1980 and 2006
}

\author{
Mauricio Bruno Ceroni Acosta ${ }^{[\mathrm{a}]}$, Marcel Achkar ${ }^{[\mathrm{b}]}$ \\ [a] Geógrafo, Mestrando em Ciências Ambientais, Faculdade de Ciências, Laboratório de Desenvolvimento Sustentável e \\ Gestão Ambiental do Território, Universidade da Republica - Uruguai, e-mail: mceroni1@yahoo.com \\ [b] Geógrafo, Doutor em Ciências Agronômicas (ENSAT-Francia), Laboratório de Desenvolvimento Sustentável e Gestão \\ Ambiental do Território, Faculdade de Ciências, Universidade da Republica - Uruguai, e-mail: achkar@fcien.edu.uy
}

\begin{abstract}
Resumo
A variabilidade climática nos últimos anos aumentou de maneira significativa e o aumento dos gases do efeito estufa é uma das causas do cenário atual. Este novo cenário repercute nos processos que ocorrem no ciclo hidrológico. A produção de gado (ovino, bovino de carne e leite), atividade fortemente ligada às raízes históricas do país, principalmente na formação do espaço agrário, depende da disponibilidade da água para os animais beberem, além daquela utilizada para produção das forragens. Neste marco, objetiva-se o estudo da disponibilidade da água no rodeio do gado no país, durante o período de 1980 a 2006. O desenho metodológico baseia-se na elaboração de um sistema de informação de dados meteorológicos e do gado espacializados. A partir dos dados, realiza-se a construção de uma variável, chamada Disponibilidade Potencial da Água do Rodeio do Gado (DARG). O desenvolvimento da pesquisa evidencia a variabilidade do espaço e tempo dos fatores edafoclimáticos, os quais condicionam os processos da produção do gado em todo o país, evidenciando uma distribuição desigual dos comportamentos.
\end{abstract}

Palavras-chave: Balanço hídrico. Gado. Uruguai. 


\begin{abstract}
In the last years climatic variability has significantly increased, and the increase of greenhouse gases are some of the causes that produced this new scenery. One of the many causes of this process is the disequilibrium in the spatial distribution of water differentially affecting the zones of the planet. The livestock production (ovine, bovine meat and milk), an activity strongly linking to the historic country roots principally to the organization of the agrarian space, depends on the water availability for the forage production and the animals watering holes. The objective of this work is to study the water availability for the Uruguayan livestock rodeo in the period between 1980 and 2006. The methodological design consists in a spatially livestock and meteorological data information system elaboration. We carry out the construction of a variable that represent the potential water availability of the livestock rodeo. This research shows that the spatially and temporal edaphic-climatic factors variability determines the processes of livestock production in the whole country, showing an unequal distribution of the performances.
\end{abstract}

Keywords: Water balance. Cattle farming. Uruguay.

\title{
Introdução
}

A água é um composto fundamental no desenvolvimento da vida, intervindo em quase todos os níveis da organização da matéria. Sua distribuição é desigual no espaço e no tempo. As sociedades humanas podem utilizar somente $0,285 \%$ do total existente na hidrosfera (ACHKAR et al., 2004). A distribuição do consumo, em nível global, entre as principais atividades é: agricultura 70\%, indústria 23\% e uso doméstico $7 \%$ (FALKENMARK, 1997). O desempenho produtivo gerou uma série de impactos tanto qualitativos como quantitativos, que condicionam a renovabilidade da água na escala humana.

O setor agropecuário em geral está condicionado pelo funcionamento do Ciclo Hidrológico, já que é fortemente dependente da utilização da água para a realização de suas atividades. Dito setor integra muitas atividades produtivas fundamentais para o desenvolvimento das comunidades humanas. O Uruguai encontra-se numa região onde a geração de produtos agropecuários encontra condições e contextos favoráveis, constituindo-se numa das principais atividades econômicas que apresenta o país. A importância do manejo da água no gado é determinante para seu desenvolvimento, tanto para produção de forragens como para o consumo direto dos animais.

Em um contexto de crescimento da variabilidade climática, em âmbito global, principalmente da temperatura e da precipitação, o funcionamento do Ciclo Hidrológico é afetado. Segundo os dados de Haylock et al. (2006) dos últimos 100 anos, o Uruguai não fica de fora destas mudanças, registrando-se:

- aumento da temperatura média em $0,8^{\circ} \mathrm{C}$. Acontecendo maiores evidências na primavera e no verão. Também a temperatura média no inverno se incrementou e os períodos de geadas (tempo entre a primeira e a última do ano) são menores e sua severidade e frequência se reduziram;

- aumento da precipitação em torno de 30\%, partindo de $1.000 \mathrm{~mm}$ anuais no princípio do século XX até uns $1.300 \mathrm{~mm}$ no fim do século, com máximos na primavera e no verão.

Estes comportamentos, acentuados nos últimos 30 anos, põem em evidência a necessidade de estudos que aprofundem e aportem elementos para alcançar maior compreensão da temática.

A importância que tem o setor do gado dentro da economia do Uruguai, a alta porcentagem da ocupação de solo na totalidade do território e o peso cultural do gado no país justificam a necessidade de trabalhos que avaliem a disponibilidade da água no marco de um aumento da variabilidade climática.

O enfoque espacial e temporal outorga um potencial para relacionar os fenômenos que existem no território. O espaço geográfico como eixo central é visto como uma categoria de análise que permite reconhecer seus elementos internos, em especial a conformação do território (SPOSITO, 2004; SUERTEGARAY, 
2000). No território uruguaio, relacionam-se em forma integrada dois elementos centrais: de um lado, o funcionamento e a evolução do clima (natureza artificializada ${ }^{1}$ ) intervindo em todos os processos de estruturação e configuração; do outro lado, a atividade do gado como construção social intervindo no conjunto das relações sociais que configuram e modelam o espaço. As relações entre ambos os elementos concretizam um território específico, caracterizado pela apropriação e dominação que as pessoas envolvidas nesse processo realizam dos recursos naturais.

O objetivo geral do presente estudo é a avaliação da variabilidade espaço-tempo da disponibilidade da água para o gado no território uruguaio entre 1980 e 2006.

\section{Metodologia}

O trabalho abrange a totalidade do território uruguaio, cuja extensão é de $176.215 \mathrm{~km}^{2}$, localizado no sudeste da América do Sul, entre os paralelos $30^{\circ}$ e $35^{\circ}$ latitude Sul e os meridianos $53^{\circ}$ e $58^{\circ}$ de longitude Oeste.

$\mathrm{Na}$ Figura 1 observa-se a estratégia metodológica aplicada durante o desenvolvimento do estudo.

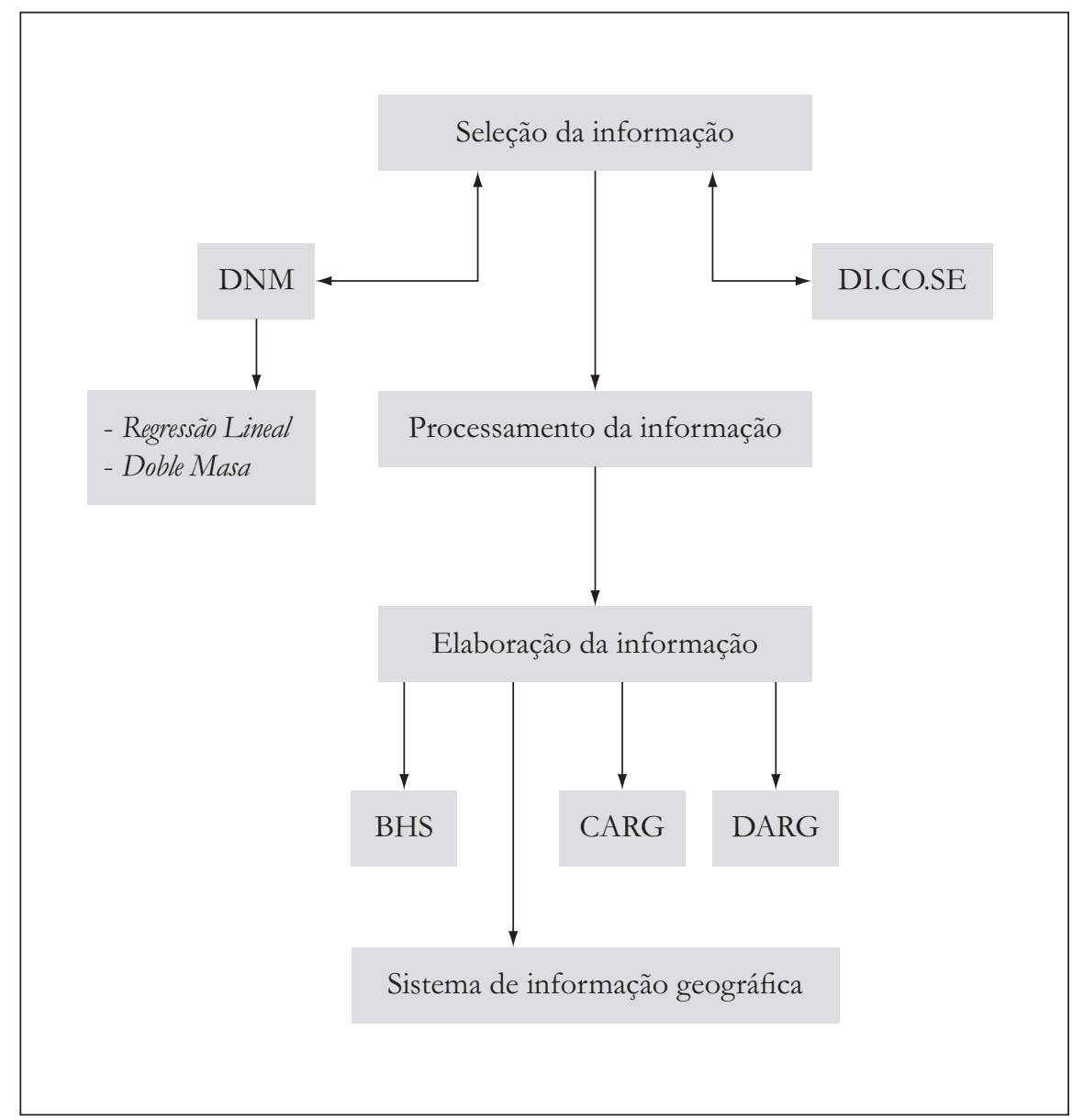

Figura 1 - Esquema geral da estratégia metodológica desenvolvida durante o presente estudo

1 Segundo Santos (1996), a sociedade intervém em quase todos os processos de produção da natureza. Grande parte do conhecimento desta, na atualidade, articula-se com a dinâmica social na busca de impactos ambientais (SUERTEGARAY, 2004). 
A seleção da informação se baseou em duas fontes: a primeira pertencente à Direção Nacional de Meteorologia (DNM), dados da média mensal de temperatura e o acumulado total mensal de precipitação, e a segunda, à División de Contralor de Semovientes (Dicose), dados do total anual de cabeças dos três subsetores de gado (ovinos, bovinos de carne e leite).

Para a seleção dos dados meteorológicos, consultou-se uma rodada de peritos, com a informação disponível que apresenta a DNM para determinar, a priori, o grau de confiabilidade destes. Baseado nesta consulta, decidiu-se trabalhar a partir de 1980 até 2006, concentrado nas 18 estações meteorológicas, as quais contêm dados para o intervalo de tempo proposto para o estudo. Como a precipitação é uma variável aleatória, optou-se por ampliar o número de estações para alcançar maior representatividade no espaço e maior confiabilidade nos resultados (CLARKE, 2006; REMENIEIRAS 1974). Neste sentido, foram selecionadas 33 estações pluviométricas, totalizando 51 para a precipitação e 18 para a temperatura (Figura 2).

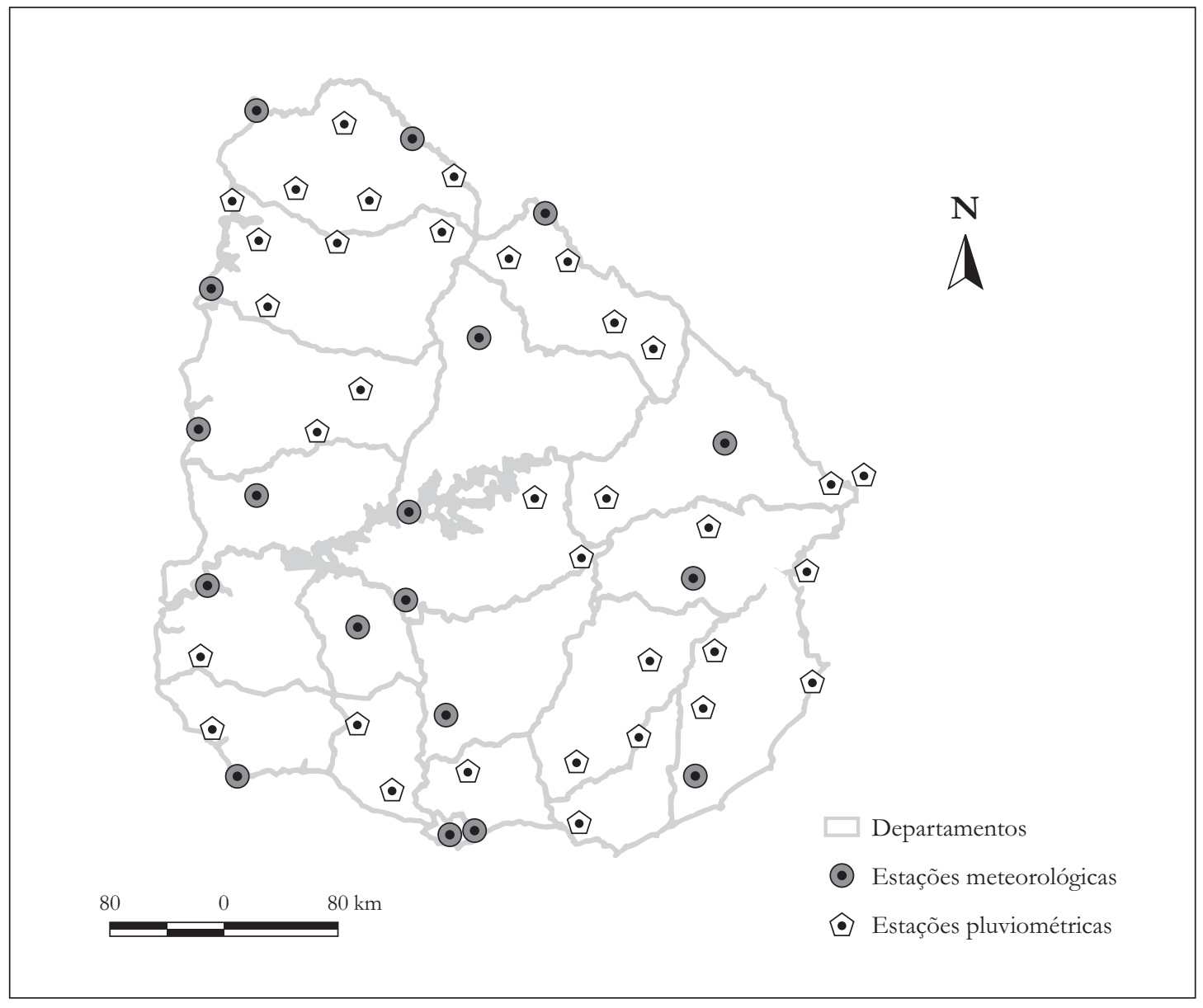

Figura 2 - Localização das estações utilizadas no presente estudo Fonte: DNM. Elaboração: Maurício Ceroni.

Em relação aos dados do gado, obtiveram-se em âmbito departamental para o mesmo período dados de 19 departamentos. Depois desta seleção, passou-se à unicidade das escalas espaciais e temporais, já que a priori existiam diferenças por se tratar de informações de diferentes origens. Para a escala espacial, optou-se por trabalhar em âmbito departamental, enquanto em nível temporal, utilizou-se a escala mensal. 
Depois da armação das bases de dados meteorológicos e do gado, passou-se ao processamento e à análise da informação.

Este procedimento se centrou na informação pluviométrica por vários motivos: por um lado, a precipitação é uma variável que atende à maior quantidade de dados (16524); por outro, apresenta um comportamento não paramétrico (CLARKE, 2006) e, finalmente, os dados não apresentam os controles de confiabilidade que registram as estações meteorológicas (ABBOT'T, 1986; BRYANT, 1979; REMENIEIRAS, 1974).

Para avaliar a confiabilidade, trabalhou-se com os métodos diretos, Doble Masa e Regressão Lineal. Para as situações em que os valores apresentavam um nível de não confiabilidade longo, foram usados métodos indiretos como os desenvolvidos pela Nasa TRMM (Tropical Rainfall Measuring Misión).

Depois disso, elaboraram-se as respectivas variáveis para avaliar a disponibilidade potencial da água para o gado. A primeira variável foi o Balanço Hídrico Superficial (BHS), mediante a fórmula (1) proposta por Achkar (2005), modificada de Lefevre et al. (1983).

$$
\operatorname{BHS}(\mathrm{n})=\mathrm{P}(\mathrm{n})+\mathrm{RR}(\mathrm{n}-1)-\mathrm{RUR}(\mathrm{n})-\operatorname{ETR}(\mathrm{n})
$$

Onde:

$\mathrm{P}(\mathrm{n})=$ é a precipitação total acumulada no mês $\mathrm{n}$

$\mathrm{RR}(\mathrm{n}-1)=$ reserva da água no solo correspondente ao mês anterior (n-1)

$\operatorname{ETR}(\mathrm{n})=$ evapotranspiração real

$\operatorname{RUR}(\mathrm{n})=$ reserva útil da água no solo no mês $\mathrm{n}$

Para a elaboração da ETR, aplicaram-se várias etapas. Em primeiro lugar, trabalhou-se com o método elaborado por Thornthwaite (1948) para o cálculo da evapotranspiração potencial (ETP). Posteriormente, ajustaram-se os valores por meio de um coeficiente de correção $(\mathrm{K})$ que considera a latitude e os meses do ano, informação tabulada pela Unesco (1982), e finalmente se considerou os valores de retenção da água nos solos.

A aplicação do método de Thornthwaite (1948) se justifica pela pouca disponibilidade de dados de outras variáveis, como radiação, velocidade do vento, tipo e estado de crescimento da vegetação. Essas variáveis requerem outros métodos, e o país não apresenta seus registros com tanta antiguidade. Além disso, a aplicação também se justifica pela série temporal com a qual se trabalhou por 27 anos, e porque a cobertura vegetal mais recomendada é o pasto natural, adaptando-se em muitos casos ao uso predominante do país (80\% do território nacional).

Para o cálculo da reserva da água no solo, elaborou-se um valor médio, com base nos dados elaborados por Molfino e Califra (2001; MAP, 1976). Para o início do cálculo da série, em janeiro de 1980, assumiu-se que o solo estava saturado.

A segunda variável desenvolvida foi o Consumo da Água do Rodeio do Gado (CARG), que decorre da fórmula (2). A determinação do CARG baseou-se em uma profunda revisão da literatura, principalmente para ajustar os diferentes elementos que agem e afetam a água dos animais, no território uruguaio.

Sendo:

$$
\mathrm{C}_{\mathrm{t}}=\mathrm{S} \times \mathrm{C}_{\mathrm{p}} \times \mathrm{D}
$$

$\mathrm{C}_{\mathrm{t}}=$ consumo total da água do rodeio do gado por departamento

$\mathrm{S}=$ estoque anual de cabeças por departamento

$\mathrm{C}_{\mathrm{p}}=$ consumo médio por dia por animal

$\mathrm{D}=$ número de dias do mês

$\mathrm{O}(\mathrm{S})$ foi obtido por meio do Dicose, enquanto que para determinar o (Cp) foi necessário o conhecimento do coeficiente $a$. A construção do coeficiente $a$ baseia-se em procurar a melhor aproximação fiável da realidade, sabendo que existem variáveis que afetam o consumo. No entanto, esse não foi considerado, uma vez que a informação não existe no país. Neste sentido, o coeficiente considera a temperatura 
e o peso do animal, não levando em conta a quantidade de matéria seca consumida e a porcentagem de sal nesta área. De acordo com os autores Bavera (1979, 2005), Church (1974) e Miller (1989), os fatores que influenciam o consumo da água são a temperatura e o consumo de matéria seca. Cabe destacar que, considerando o peso, indiretamente se está considerando o consumo de matéria seca (BAVERA, 1979; MILLER, 1979).

Para se obter um comportamento mais aproximado do $\left(\mathrm{C}_{\mathrm{p}}\right)$, utiliza-se a temperatura média mensal, sendo o $\left(\mathrm{C}_{\mathrm{p}}\right)$ o produto do coeficiente $(a)$ pela temperatura média mensal $\left(\mathrm{T}_{\mathrm{M}}\right)$, conforme apresentado na fórmula (3).

Sendo:

$$
\mathrm{C}_{\mathrm{p}}=a . \times \mathrm{T}_{\mathrm{M}}
$$

$\mathrm{T}_{\mathrm{M}}=$ Temperatura média mensal por departamento

$a=$ Coeficiente de consumo

Sendo:

$$
a=\mathrm{T} / \mathrm{C}
$$

$\mathrm{T}=$ temperatura ambiente (CERONI, 2008)

$\mathrm{C}=$ consumo em relação à temperatura ambiente (CERONI, 2008)

Como o peso corporal é uma variável determinante no CARG, foram utilizados os dados da Direção Agrícola Estatística e Censos (DIEA), com a consulta a alguns funcionários da DIEA para determinar o tipo de animal mais representativo. Para bovinos de carne utilizou-se o peso de novilhos de $273 \mathrm{~kg}$; já para bovinos de leite, foi utilizado peso maior que $409 \mathrm{~kg}$, com uma média de 18 litros de leite por dia, enquanto que para os ovinos o peso foi de $60 \mathrm{~kg}$.

A terceira variável foi a elaboração da Disponibilidade da Água no Rodeio do Gado (DARG). A construção da DARG consistiu em uma base sistêmica, condicionada por componentes de entradas e saídas; neste caso, o sistema resulta da entrada dos cálculos da BHS e da saída do CARG. Para ajustar os resultados da DARG elaborou-se uma variável de entrada, a urina presente na entrada da água no sistema. A fórmula (4) determina o cálculo da urina fornecida pelos animais.

Sendo:

$$
\mathrm{O}_{\mathrm{t}}=\mathrm{O}_{\mathrm{p}} \times \mathrm{S} \times \mathrm{D}
$$

$\mathrm{O}_{\mathrm{t}}=$ urina total por departamento

$\mathrm{O}_{\mathrm{p}}=$ urina média por dia por animal

$\mathrm{S}=$ estoque anual de cabeças por departamento

$\mathrm{D}=$ número de dias que tem cada mês

Uma vez obtida a informação em relação ao aporte da água por urina, procedeu-se à integração dos dados. Com a base de dados de BHS, a soma de ambas as bases permitiu obter o ingresso total da água ao agrossistema do gado (fórmula 5).

Sendo:

$$
\mathrm{I}_{\mathrm{t}}=\mathrm{O}_{\mathrm{t}}+\mathrm{BHS}
$$

$\mathrm{I}_{\mathrm{t}}=$ ingressos totais da água do rodeio gado

$\mathrm{O}_{\mathrm{t}}=$ urina total por departamento

BHS = balanço hídrico superficial

Posteriormente, cruzou-se informação do $\mathrm{I}_{\mathrm{t}}$ com $\mathrm{C}_{\mathrm{t}}$, integrando os aportes que chegam ao agrossistema do gado com as saídas. A relação entre ambas determina a disponibilidade potencial da água para o rodeio do gado $\left(\mathrm{D}_{\mathrm{t}}\right)$ (fórmula 6 ). 
Sendo:

$$
D_{t}=I_{t}-C_{t}
$$

$\mathrm{D}_{\mathrm{t}}=$ disponibilidade potencial da água do rodeio do gado

$\mathrm{I}_{\mathrm{t}}=$ ingressos totais da água ao rodeio do gado

$\mathrm{C}_{\mathrm{t}}=$ consumo total da água do rodeio do gado

A última fase da metodologia consistiu na geração de cartografia temática, a escala departamental, a partir da construção de um Sistema de Informação Geográfica (SIG). Os SIGs são sistemas complexos de gestão da informação que incluem um banco de dados com o potencial para armazenar, processar e analisar os dados espacialmente referenciados (GOMES, 2002). A base do SIG está composta pelo programa ArcView GIS ${ }^{\circledR}$ versão 3.2 extensão “Image Analysis" e "Análise Espacial” (produtos desenvolvidos pela Esri ${ }^{\circledR}$ Inc.USA) e "Polygeom" (um produto desenvolvido pelo Ifremer ${ }^{\mathbb{B}}$ França). Optamos por este conjunto de programas para facilitar o intercâmbio de informações, com a fácil operacionalidade dos dados apresentados, sem a necessidade de mudanças no formato.

O procedimento foi baseado na construção e concepção de quadros de entrada dos respectivos bancos de dados, por meio das principais variáveis que permitiram a integração do sistema de informação. Este processo levou à especialização e vetorização da informação em forma de polígonos das três bases de dados.

No caso dos dados meteorológicos, foi necessário estabelecer um modelo de distribuição contínua (MDL). Este processo foi feito por meio de uma interpolação espacial dos 12 pontos mais próximos com valores reais, considerando a unidade espacial mínima (pixel) de $1 \mathrm{~km}$, gerando um mosaico contínuo e abrangendo toda a área, dando maior peso de influência para o mais próximo e menos peso para as zonas mais afastadas. O resultado deste processo gera uma matriz modelo com uma unidade territorial contínua de pixel de $1 \mathrm{~km}$.

\section{Resultados}

\section{Balanço Hídrico Superficial (BHS)}

A geração dos resultados centrou-se na construção de três bases de dados digitais, extensivas, concisas e sistematizadas para todo o país à escala departamental.

O comportamento do BHS em nível espacial tem uma distribuição em um padrão de crescimento do Sudoeste ao Nordeste, enquanto a temporalidade se diferencia em três grandes períodos: de dezembro a março, menores registros; de abril a julho, maiores registros; e de agosto a outubro, registros intermediários.

A variabilidade espaço-temporal do BHS foi diferenciada para a totalidade do país, situação importante se considerada a pouca extensão territorial do Uruguai. A distribuição espacial teve um padrão de crescimento Sudoeste-Nordeste, onde o departamento de Colônia apresentou menor registro da média anual acumulada para o conjunto da série, enquanto o departamento de Artigas registrou a maior. A distribuição temporal ocorreu de maneira bimodal para todo o país, oscilando de maneira distinta segundo cada um dos departamentos.

\section{Consumo da Água do Rodeio do Gado (CARG)}

A distribuição espacial do CARG aconteceu de maneira diferencial no Sul com valores mínimos; no Centro-Leste e Centro-Oeste valores intermediários; e no Norte valores maiores. A distribuição temporal teve um forte componente térmico, e os menores consumos ocorreram em junho e julho; os consumos intermediários de abril a maio e de agosto a novembro; e os maiores consumos de dezembro a março.

A variação espacial do CARG foi diferenciada para todo o país, com uma componente forte da inter-relação dos fatores que afetaram o consumo, situação que se materializou na distribuição dos consumos departamentais. Os maiores consumos se apresentaram ao norte (Departamento de Artigas e Salto). Em relação 
à temporalidade do comportamento, foi mais fácil determinar uma distribuição, sendo os meses mais quentes os de maiores consumos, enquanto os mais frios foram de menores consumos.

\section{Disponibilidade da água do rodeio de gado (DARG)}

A relação temporal-espacial da DARG em relação ao CARG e ao BHS teve dependência quase exclusiva com o BHS, já que a correlação linear foi de 0,99 . Esta resposta se refletiu na semelhança dos resultados de ambas as variáveis.

Para poder visualizar de forma mais clara os processos que ocorreram dentro de cada departamento, na Figura 3 observa-se a distribuição dos 324 meses trabalhados, associados os seus comportamentos em relação à média e ao desvio padrão. Para identificar as tendências e comportamentos, classificaram-se os dados em quatro gamas. A primeira categoria localiza-se abaixo do desvio padrão; a segunda categoria concentra-se abaixo da média e acima do desvio padrão (faixa de cor vermelha); a terceira categoria localiza-se acima da média e por baixo do desvio padrão (faixa de cor vermelha); a quarta categoria se concentra acima do desvio padrão.

Para o exemplo do departamento de Tacuarembó, a situação refletiu 43,5\% dos meses que registraram valores abaixo da faixa desvio padrão, 12,9\% abaixo da média e acima da primeira faixa de desvio padrão, $19,7 \%$ acima da média e abaixo da segunda faixa de desvio padrão, e 23,7\% dos meses com valores acima do desvio padrão. Este comportamento demonstrou que foi um departamento que não deveria apresentar dificuldades na disponibilidade da água, já que, como se observa na Figura 3, todos os valores são positivos.

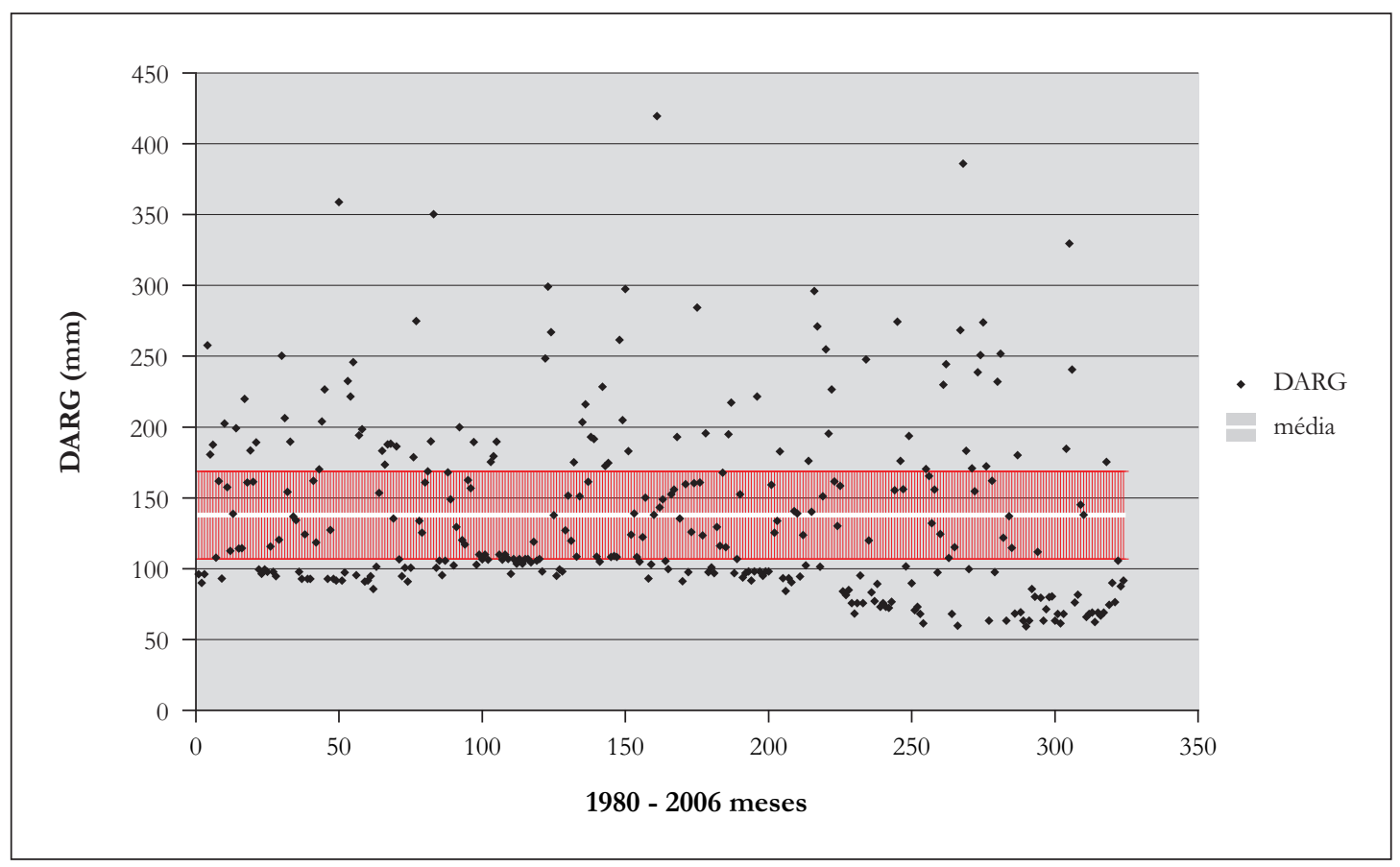

Figura 3 - Distribuição mensal da DARG, em relação à média e ao desvio padrão da série 19802006, no Departamento de Tacuarembó

Fonte: DNM, NRC, ASAE, DICOSE. Elaboração: Maurício Ceroni.

A escala de análise mensal registrou menor disponibilidade nos meses de dezembro, janeiro, fevereiro e março. De abril a julho registraram-se os valores médios mais elevados, enquanto de agosto a novembro os valores foram intermediários. Portanto, o departamento de Tacuarembó apresentou um período de menor 
disponibilidade da água, que ocorreu de dezembro a março, um período transicional intermediário de agosto a novembro, e o período de maior disponibilidade de abril a julho.

Identificou-se uma tendência à queda durante a totalidade da série, associada aos maiores registros que existiram abaixo do desvio padrão durante os últimos dez anos.

O aumento na variabilidade que ocorreu em Tacuarembó, principalmente durante os últimos dez anos, manifestou uma situação complexa de difícil prognóstico; por tal motivo, é relevante o seguimento do comportamento ao longo do tempo, com a aplicação de programas de contingência, diminuindo os efeitos das tendências registradas nos comportamentos.

\section{Discussão}

O desenvolvimento da investigação revelou a vulnerabilidade do Uruguai em relação à pesquisa quantitativa do consumo da água pelo animal. Experimentam-se alguns progressos no gado de leite, mas no gado de carne e ovino a investigação é praticamente inexistente. Esta evidência se vê agravada pela influência do gado no processo histórico-cultural e econômico para o país.

A escolha da série temporal (1980-2006) permitiu aproximar os resultados de um comportamento médio. A aplicação dos distintos métodos para avaliar a confiabilidade dos dados permitiu que a base de dados não só fosse ampla, mas também de caráter confiável para a análise desenvolvida e para sua aplicação em futuras pesquisas.

A seleção da unidade espacial (os departamentos) apresenta uma limitação importante desde o ponto de vista sistêmico, já que não coincide com limites naturais; portanto, para trabalhar em uma planificação agropecuária real, deve-se transitar por uma unidade territorial natural - por exemplo, as bacias hidrográficas, que são um sistema territorial adequado. Mesmo que esta limitante seja clara, sobretudo pensando em planificações em médio e longo prazo, a mudança para unidades de bacia implica mudar as bases de dados dos registros do gado do país, processo que deve começar a transitar. Portanto, em curto prazo, a visão mais ou menos hegemônica que para técnicos e políticos se ajusta mais à realidade é a unidade departamental. Neste sentido, a resolução espacial deste estudo constitui um aporte para conseguir transformações rápidas no tempo.

\section{Conclusão}

Existem regionalizações diferenciais no comportamento da DARG no Uruguai, que ocorrem em distintas escalas temporais. Anualmente, os menores valores de disponibilidade da água se registraram principalmente no Sudoeste, enquanto os maiores registros se localizaram no Noroeste do país. O nível médio apresentou um comportamento cíclico que repercutiu na mudança da regionalização, destacando-se uma diferenciação principal entre o verão e o fim do inverno.

O sistema de informação permitiu o desenvolvimento de três bancos de dados inexistentes para o país, dos quais, para o CARG e a DARG, criou-se uma metodologia sem antecedentes. Também permitiu ter informação climática espacialmente contínua para todo o país, o que facilita o acesso a qualquer dos valores de forma rápida e clara.

A análise do trabalho mostrou que os componentes do tempo-espaço nos recursos naturais, neste caso da água aplicada a um ramo de produção, são de elevado potencial para avançar rumo a cenários de sustentabilidade dos recursos, bem como da própria população.

\section{Agradecimentos}

Aos colegas do Laboratório e a Daniel Facco, pela tradução do texto. 


\section{Referências}

ABBOTT, P. Guidelines on the quality control of surface climatological data. WCP-85, Geneva, n. 111, p. 65, 1986.

ACHKAR, M. et al. Hacia un Uruguay sustentable: gestión integrada de cuencas hidrográficas. Montevideo: Redes; Uruguay sustentable, 2004.

ACHKAR, M. Evaluación de la distribución de la materia orgánica del horizonte superficial del suelo mediante el uso de imágenes satelitales. Aplicación de metodología SIG: caso, cuenca del arroyo Sánchez Uruguay. 2005. 145 f. Tesis (Doctorado en Ciencias Ambientales) - Escuela Nacional de Ciencias Agrarias (ENSAT), Toulouse, 2005.

BAVERA, G. et al. El agua en el organismo animal. In: BAVERA, G. et al. Aguas y aguadas. Buenos Aires: Hemisferio Sur, 1979. p. 5-25.

BAVERA, G. Aguas para bebida de bovinos. In: BAVERA, G. Marca líquida agropecuaria: la información nacida en su campo. Córdoba: Marca Líquida Agropecuaria SH, Año XV, n. 143, p. 17-19, 2005.

BRYANT, G. Archiving and quality control of climatological data. Meteorological Magazine, v. 180, p. 309-315, 1979.

CERONI, M. Análisis espacio-temporal del balance hídrico en Uruguay: disponibilidad de agua para el rodeo Ganadero 1980-2006. 2008. 150 f. Tesis (Licenciatura en Geografía) - Facultad de Ciencias, Universidad de la Republica, Montevideo, 2008.

$\mathrm{CHURCH}$, D. et al. Metabolismo hídrico y requerimientos de agua. In: $\mathrm{CHURCH,} \mathrm{D.} \mathrm{et} \mathrm{al.} \mathrm{Fisiología} \mathrm{digestiva} \mathrm{y}$ nutrición de los rumiantes. Zaragoza: Acribia, 1974. v. 2, p. 1-21.

CLARKE, R. Análisis estadístico de eventos extremos en un contexto no estacionario In: BARROS, V.; CLARKE, R.; SILVA DIAS, P. El cambio climático en la cuenca del Plata. Buenos Aires: CONICET, 2006. p. 209-226.

FALKENMARK, M. Meeting water requirements of an expanding world population. Estocolmo: Natural Science Research, 1997.

GOMES, M. Abordagem metodológica de elaboração e uso de SIG em bacias hidrográficas: contribuição à educação ambiental. 2002. 303 f. Dissertação (Mestrado em Geografia) - Faculdade de Ciências e Tecnologia, Universidade Estadual Paulista, Presidente Prudente, 2002.

HAYLOCK, M. R. et al. Trends in total and extreme South American rainfall in 1960-2000 and links with sea surface temperature. Journal of Climate, v. 19, p. 1490-1512, 2006.

LEFEVRE-FONOLLOSA, M-J. Télédétection d'anomalies géobotaniques appliquée à la recherche minière. 1983. 268 f. Thèse (Doctorat en Traitement d’Image) - Université Paul Sabatier, Toulouse, 1983.

MAP, D. S. F. Carta de reconocimiento de suelos del Uruguay y leyenda explicativa, tomos I y II. Montevideo: [s.n.], 1976.

MILEER, W. Nutrición y alimentación del ganado vacuno lechero. Zaragoza: Acribia, 1979.

MOLFINO, J.; CALIFRA, A. Agua disponible de las tierras del Uruguay segunda aproximación. Montevideo: DSyA - DGRNR - MGAP, 2001.

REMENIEIRAS, G. Las precipitaciones. In: REMENIEIRAS, G. Tratado de hidrología aplicada. Barcelona: Editores Técnicos Asociados, 1974. p. 64-178.

SANTOS, M. A natureza do espaço: técnica e tempo razão e emoção. São Paulo: Hucitec, 1996.

SPOSITO, E. Geografia e filosofia: contribuição para o ensino do pensamento geográfico. São Paulo: UNESP, 2004. p. 218. 
SUERTEGARAY, D. Espaço geográfico uso múltiplo. In: SUERTEGARAY, D.; BASSO, L.; VERDUM, R. (Org.). Ambiente e lugar no urbano: a grande Porto Alegre. Porto Alegre: Ed. da UFRGS, 2000. p. 13-34.

A poética do espaço geográfico. In: CONGRESSO BRASILEIRO DE GEÓGRAFOS, 6., 2004, Goiânia. Anais... Goiânia: Associação dos Geógrafos Brasileiros, 2004. p. 10.

THORNTHWAITE, G. W. An approach towards a rational classification of climate. Geographycal, n. 38, p. 59-64, 1948.

UNITED NATIONS EDUCATIONAL, SCIENTIFIC AND CULTURAL ORGANIZATION - UNESCO. Guía metodológica para le elaboración del balance hídrico de América del Sur. Montevideo: Rostlac, 1982. p. 1-130.

Recebido: 01/09/2009

Received: 09/01/2009

Aprovado: $26 / 03 / 2010$

Approved: 03/26/2010 